\title{
TRAJETÓRIA DAS MICROEMPREENDEDORAS INDIVIDUAIS NA REGIÃO METROPOLITANA DE BELÉM: CRESCIMENTO PESSOAL, EMPODERAMENTO FEMININO E A FORMALIZAÇÃO DE SEUS NEGÓCIOS
}

Flora Navarro ${ }^{1}$

Cynthia Meireles Martins ${ }^{1}$

Márcia Athayde ${ }^{1}$

Ana Maria Vasconcellos ${ }^{1}$

${ }^{1}$ Programa de Mestrado e Doutorado em Administração / Centro de Ciências Humanas e Sociais / Universidade Da Amazônia UNAMA 


\section{TRAJETÓRIA DE MICROEMPREENDEDORAS INDIVIDUAIS NA REGIÃO METROPOLITANA DE BELÉM: CRESCIMENTO PESSOAL, EMPODERAMENTO FEMININO E A FORMALIZAÇÃO DE SEUS NEGÓCIOS}

Resumo: Essa pesquisa teve como objetivo compreender a atuação da mulher microempreendedora individual - MEI, atuante na Região Metropolitana de Belém-Pa, considerando suas motivações para exercer a atividade empreendedora, a contribuição para o empoderamento feminino e as percepções acerca da formalização e do crescimento dos negócios. Trata-se de pesquisa exploratória na essência, realizada mediante análise documental, entrevistas e levantamento, realizadas em 2015. Como resultado, foi possível observar que as MEIs estão atuando em atividades diversificadas, trabalham de forma participativa, organizada e planejada e buscam conhecimentos úteis para o desenvolvimento do negócio. As microempreendedoras alegaram que implementaram ações de inovação, reduziram desperdícios e vêm tomando consciência que essas atitudes devem servir de exemplo e serem divulgadas para avanço da sustentabilidade. Conclui-se que o empreendedorismo é uma alternativa viável de inclusão social e econômica para essas mulheres, destacando-se o crescimento pessoal, o empoderamento feminino e a contribuição para o desenvolvimento da região onde atuam.

Palavras chave: Empreendedorismo. Mulheres. Microempreendedoras Individuais. Região Metropolitana de Belém.

\section{Introdução}

A inserção da mulher em atividades empreendedoras tem crescido em todo mundo, e entre os fatores que motivam essa inserção se destacam ocrescimento e a disputa acirrada no mercado de trabalho, que passa a ser vivido por homens e mulheres que, sem dúvida, pretendem igualar suas oportunidades e reconhecimento (HISRICH; PETERS; SHEPHERD, 2014).

No Brasil, a participação das mulheres nas taxas de empreendedorismo na primeira década dos anos 2000 se manteve em torno de 49\% (IBPQ, 2012). Portanto, se torna relevante conhecer sua importância no cenário econômico e as razões que as mulheres têm para empreender, as particularidades do empreendedorismo feminino, a trajetória da mulher no mercado de trabalho, setores do empreendimento, formas de gestão e consequências para a sociedade.

Vale frisar que, a despeito da relevância da participação feminina na taxa de empreendedorismo, esta não tem sido uma tarefa fácil. Gimenez (2010) afirma que as mulheres têm muitos empecilhos como, por exemplo, o acesso a fontes de financiamento e o processo sucessório nas empresas familiares, pois o pai sempre idealiza a perpetuação de seus negócios com os filhos homens. Ademais, a vida profissional e familiar confronta-se com os problemas e as oportunidades de analisar e fazer crescer um novo empreendimento, sendo que os sonhados horários flexíveis normalmente se transformam em horas extras devido à sobrecarga de trabalho.

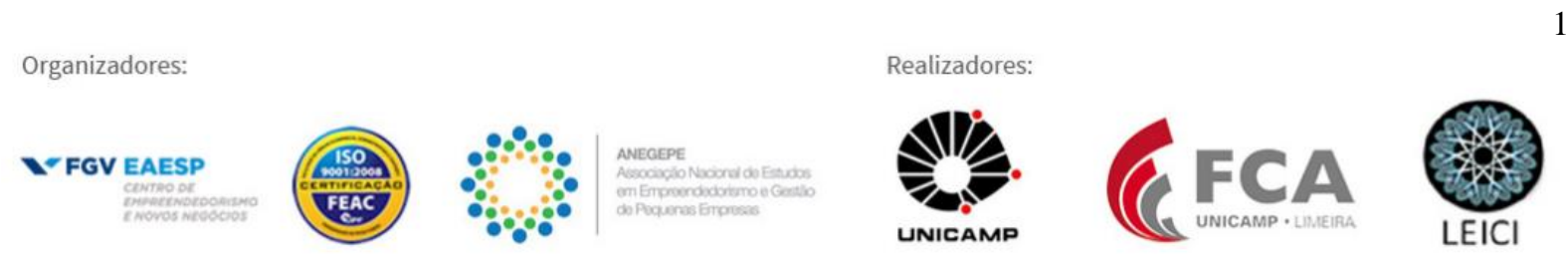


Cramer et al. (2001) complementam ao analisar que, pelo fato das mulheres serem mais sensíveis nas relações pessoais, elas se encontram em constante conflito, possuindo um sentimento de culpa tanto ao se dedicar mais à família e abrir mão de sua carreira, quanto ao se dedicar mais à carreira e abrir mão dos cuidados com a família. Teixeira e Bomfim (2016) argumentam que na tentativa de conciliar bem os múltiplos papéis, as mulheres muitas vezes se deparam com a frustração e sentimento de culpa. A empreendedora é a parte mais sacrificada, porque os cuidados a si própria estão condicionados a sobra de tempo e assim, elas se negligenciam para dar assistência afetiva aos que lhes são caros. Ademais, a busca pelo ponto de equilíbrio entre a família e o trabalho geram desgaste emocional e físico, chegando a afetar a autoestima e o moral das empresárias (TEIXEIRA; BOMFIM, 2016).

Ao criar seus negócios, estudos mostram que mulheres encontram dificuldades relacionadas com a experiência gerencial, como Machado et al. (2003), os quais identificaram que homens empreendedores possuem mais experiência do que as mulheres empreendedoras. De acordo com Carter (2001), a experiência anterior é um fator importante para o estabelecimento e a viabilidade das empresas e Cramer et al. (2001) afirmam que a experiência anterior influencia na escolha do ramo de atividade do novo negócio, uma vez que implica em habilidades para o melhor desempenho da organização. Assim, a falta de experiência gerencial contribui para acentuar as diferenças de gênero e a própria possibilidade de criação de empresas (MACHADO et al., 2010).

Mas, a despeito das dificuldades e limitações que as mulheres podem ter no processo de empreender seu próprio negócio, elas não se intimidam ou desistem. E nesse cenário, destacase uma das alternativas para as mulheres empreenderem, é a categoria de Microempreendedor Individual - MEI, que surgiu para garantir a legalidade e a formalidade dos microempresários brasileiros (Sebrae, 2015), possibilitando assim que as mulheres microempreendedoras individuais possam criar (e/ou formalizar) negócios inovadores e, assim, poderem continuar cada vez mais se desenvolvendo e crescendo no mercado.

Assim, esse trabalho tem como objetivo compreender a atuação da mulher microempreendedora individual - MEI da região metropolitana de Belém-Pa. considerando suas motivações para exercer a atividade empreendedora, a contribuição para o empoderamento feminino e as percepções acerca da formalização e do crescimento dos negócios pelas microempreendedoras.

Conforme Sobral (2010), o interesse em estudar as representações de gênero, na perspectiva das mulheres, tem como objetivo central compreender aquilo que se configura como novo no pensamento e/ou ação das mulheres, que indica um movimento de modificação nas práticas de gênero. $\mathrm{O}$ interesse em analisar a atuação das mulheres microempreendedoras individuais se dá tanto pela representatividade na criação de seus próprios negócios, como pelo desenvolvimento de novas lideranças e processos, além da necessidade de mais estudos específicos nessa área.

A inserção feminina no mercado de trabalho e, consequentemente, o incremento do número de empreendedoras motivam o interesse de pesquisas sobre o exercício do papel empreendedor por mulheres desde a década de 1990, em que as mulheres vêm iniciando empreendimentos a uma taxa 1,5 vezes maior que os homens (OECD, 1998; 2000). Estudos têm demonstrado que as mulheres abrem empresas por diferentes motivos, tais como: desejo de realização e independência, percepção de oportunidade de mercado, dificuldades em ascender

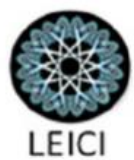


na carreira profissional em outras empresas, necessidade de sobrevivência e como uma maneira de conciliar trabalho e família (HISRICH, 1989; VOKINS IN ALLEN; TRUMAN, 1993; MOORE; BUTTNER, 1997; CROMIE, 1998; GIMENEZ et al., 1998; STILL; TIMMS, 1998). Gimenez, Ferreira e Ramos (2017) ressaltam que os estudos sobre empreendedorismo feminino no Brasil têm focado a percepção do exercício do papel empreendedor e sua importância para as mulheres, dificuldades enfrentadas e resultados obtidos, motivações para empreender e o estudo da presença de conflitos relacionados aos múltiplos papéis exercidos pelas mulheres empreendedoras, notadamente o equilíbrio entre as atividades empreendedoras e do lar. Os autores ainda articulam que o tema ainda não se consolidou como um espaço de investigação sistemática no Brasil.

Ademais, estudar a atuação das mulheres microempreendedoras da região metropolitana de Belém possibilita entender o desenvolvimento socioeconômico dos negócios na região, pois o crescimento e a evolução dos empreendimentos convergem para o desenvolvimento local, além da capacidade de mobilização, criatividade, condições de crédito e maior empoderamento das mulheres.

\section{Referencial Teórico}

\section{Mulheres, mercado de trabalho e empreendedorismo}

As transformações culturais, a queda na taxa de fecundidade e o maior nível de escolaridade são alguns aspectos que contribuem para o aumento da presença da mulher no mercado de trabalho (LINDO et al., 2007). Tais aspectos favoreceram para que $65 \%$ das mulheres brasileiras sejam inseridas no mundo do trabalho, segundo dados do Instituto Brasileiro de Geografia e Estatística (IBGE, 2009), sendo o crescimento da força de trabalho feminina no Brasil é um dos mais altos da América Latina (DAMASCENO, 2010).

Um crescimento dessa monta dificilmente aconteceria sem que dele resultasse uma importante mudança do perfil daquela que participa hoje do mercado de trabalho. De fato, até os anos 1970 a mulher brasileira que disputava posições no mundo do trabalho era majoritariamente jovem, solteira e sem filhos. Hoje ela é mais velha, casada e mãe. O aumento da taxa de participação feminina foi sustentado pela entrada no mercado de trabalho das mulheres em idades mais elevadas, ou pelo fato de que, ingressando mais jovens no mercado, dele não se retiravam ao iniciar a sua carreira reprodutiva (GUIMARÃES, 2011).

Para Belle (1993), a partir da década de 80 a mulher passou a ocupar novos postos de trabalho não mais subalternos nas organizações, mas sim cargos de responsabilidades, implicando em uma redefinição de seu papel na sociedade. Porém, a antiga estrutura patriarcal da dominação masculina ainda se via até a década de 90, encontrada na sociedade de maneira discreta, onde a mulher encontrava dificuldades no mercado de trabalho que não eram encontradas pelos homens (BELLE, 1993). Esse cenário, de maneira discreta, perdura até os dias de hoje.

Sobre formar seus próprios negócios, vale frisar que faltam estatísticas sobre mulheres empreendedoras, as quais são relevantes, pois a criação de negócios contribui para o desenvolvimento econômico, geração de empregos e outros benefícios (MACHADO et al., 2010). Contudo, estudos como de Boden Jr. (1999), Korn/Ferry (2001) e Possati e Dias (2002) destacam os principais motivos que fundamentam a opção das mulheres pelo empreendedorismo, sendo eles: sobrevivência, descoberta de um nicho de mercado, a busca de

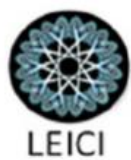


auto realização e, independência e/ou estabilidade financeira. Todos esses motivos levaram as empreendedoras a construírem uma autoimagem de vencedoras, elevando sua autoestima. Ademais, como empreendedoras, possuem maior liberdade de ação, na medida em que percebem o empreendimento próprio como capaz de viabilizar esquemas mais flexíveis de trabalho e convivência familiar, a despeito de em alguns casos aumentar sua jornada de trabalho.

Bourne (2010) ressalta ainda o caráter de novidade nas vivências das mulheres, que desfaz - através de palavras, gestos, atitudes, comportamentos e sentimentos - o ideal histórico e indenitário de dona de casa, de doméstica e mãe, e de fragilidade que identifica a mulher. Esse caráter refaz a representação feminina, levando a procurar experimentar novas práticas de gênero no seu cotidiano, envolvendo relações familiares, trabalho e atividades políticas, em uma distinção entre o comportamento privado e o público, no qual o privado se caracteriza pela privacidade, pela propriedade, pela intimidade, pela ausência e invisibilidade social para o mundo e o público caracteriza-se pela visibilidade, pela existência de um espaço comum, pela liberdade e pela manutenção do alimento.

Revela-se, assim, que o quadro motivacional que impulsiona as mulheres brasileiras a criarem/conduzirem seus próprios empreendimentos encontra respaldo nos estudos realizados com empreendedoras de outras culturas (ANDERSON; WOODCOK, 1996; MOORE; BUTTNER, 1997). Os primeiros estudos sobre mulheres empreendedoras foram realizados na América do Norte (Estados Unidos e Canadá) e tiveram como objetivo identificar o perfil de mulheres, que em sua maioria buscavam em seus novos negócios a independência. Machado et al. (2003) também destacaram razões econômicas, sociais e psicológicas que levaram parte destas mulheres a empreender, razões circunstanciais ou determinadas pela vontade pessoal de empreender. Porém, estas iniciavam com pouco capital e se deparavam com dificuldades em conciliar o trabalho e a família, em participar de redes de negócios, bem como obter o capital para seus negócios (MACHADO et al., 2010).

Freitas e Teixeira (2016) observaram que, entre os motivos que levam a mulher a empreender se destacam o sucesso do desenvolvimento de uma oportunidade anterior, a visualização de sucessos de terceiros, o histórico familiar e a possibilidade e satisfação de tomar as próprias decisões e decidir os rumos do empreendimento. Em sua pesquisa, os autores perceberam que a intuição, as habilidades interpessoais e o forte apoio familiar são determinantes na identificação das oportunidades de criação e continuidade dos negócios par mulheres empreendedoras (FREITAS; TEIXEIRA, 2016).

Já na pesquisa de Cortez, Ferreira, Ferreira e Araújo (2016) os autores identificaram que as mulheres empreendem por motivações pessoais, por paixão pelo negócio, coragem, força de vontade, iniciativa e autoconfianças. Os autores sugerem que nas fases iniciais, períodos que envolvem a descoberta e exploração de uma oportunidade, as empreendedoras agem motivadas principalmente pela afetividade.

O Brasil é apresentado como o país que possui a maior Taxa de Empreendedores em Estágio Inicial - TEA do G20 (um grupo formado pelos ministros de finanças e chefes dos bancos centrais das 19 maiores economias do mundo mais a União Europeia), com 17,5\%, seguido pela China, com $14,4 \%$ e a Argentina com 14,2\%, demonstrando a tendência de crescimento da atividade empreendedora (DORNELAS, 2011).

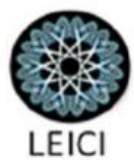


A inserção feminina no mercado de trabalho e, consequentemente, o incremento do número de empreendedoras nas duas últimas décadas motivaram o interesse de pesquisas sobre o exercício do papel empreendedor por mulheres (OECD, 2000). Allen e Truman (1996) ressaltam que, no ano de 1993, na Alemanha e na Dinamarca, para cada três empresas criadas, uma era iniciada por mulher, variando uma em cada quatro na França e uma em cada cinco empresas na Grécia, Espanha, Itália, Irlanda e Reino Unido. Também em outros países, o empreendedorismo feminino tem aumentado e o resultado é que as mulheres estão iniciando empresas a uma taxa 1,5 vezes maior que os homens (OECD, 1998).

No Brasil, a crescente participação das mulheres no empreendedorismo indica o grande potencial econômico e a significativa contribuição do mesmo para o desenvolvimento do país. Neste sentido, cumpre observar que, de acordo com a última pesquisa publicada pelo Global Entrepreneurship Monitor (GEM) em 2009, pela primeira vez o contingente de mulheres empreendedoras brasileiras (53\%) superou numericamente o de empreendedores homens $(47 \%)$, tanto no empreendedorismo por oportunidade quanto no empreendedorismo por necessidade, sendo que o Brasil se consagrou como o terceiro país mais empreendedor do mundo.

O anuário das mulheres empreendedoras e trabalhadoras em micro e pequenas empresas - Sebrae - em parceria com o DIEESE, entre os anos 2001 e 2011 diz que a Região Norte foi a que teve maior crescimento de mulheres empreendedoras no país. O número de mulheres que montou o seu negócio cresceu quase $80 \%$ no período destacado (SEBRAE, 2012).

De acordo com as pesquisas no Sebrae GEM (2012) foi possível constatar que os principais benefícios que motivam os Empreendedores Individuais a formalizarem seus negócios estão na oportunidade de legalizar suas atividades de maneira simplificada e assim ter acesso a benefícios que serão importantes para seus negócios, buscando através do MEI, trabalhar de forma digna e exercer sua cidadania perante a sociedade. Ademais, as mulheres buscam, portanto, não só maior inserção no mercado, mas a garantia de vantagens que podem mudar o cenário do crescimento de seu negócio.

Nesse sentido, Cortez et al. (2016) destacam o interesse pelo conhecimento das mulheres empreendedoras. Os autores identificaram que as empreendedoras da cidade do Natal (RN) iniciam suas trajetórias movidas pelo desejo ou pela oportunidade de fazerem o que gostam e se apoiam principalmente nas relações de família e amigos. Mas após a fase inicial do empreendimento, as mulheres demonstraram a procura pelo conhecimento técnico e formal, e pela busca pela realização de cursos, tais como os oferecidos por órgãos como o SENAC (Serviço Nacional de Aprendizagem Comercial), além do interesse pelo estudo frequente de tendências, mercados e modos de trabalho por meio da internet.

Bottane e Lima (2012) ressaltam através de seus estudos que, entre os fatores que motivaram os Empreendedores Individuais a formalizarem seus negócios, destacaram-se o fato dos trabalhadores encontrarem oportunidade de legalizar suas atividades de maneira simplificada e assim, ter acesso a benefícios, que serão importantes para seus negócios, e buscando através do MEI, trabalhar de forma digna e exercer sua cidadania perante a sociedade. Ainda, de acordo com Santos et al., (2012), a legalização possibilita a obtenção de informações acerca dos ramos de atividades, localização, condições gerais do empreendimento entre outros fatores fundamentais que nortearão o governo quanto ao conhecimento da realidade acerca desses empresários e a definição de novas políticas públicas para a inclusão e o

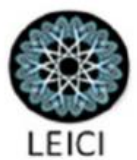


desenvolvimento econômico e social. Isso mostra que a formalização permite a organização e a dedicação do MEI em controlar e administrar o próprio negócio com mais responsabilidade refletindo no bom desenvolvimento, e no compromisso de longo prazo consigo mesmo e com a sociedade.

Mas, por outro lado, mulheres empreendedoras enfrentam dificuldades de toda ordem para empreender. Conforme Alperstedt, Ferreira e Serafim (2014), em pesquisa cujo objetivo geral consistiu em analisar os problemas encontrados ao longo do processo empreendedor de mulheres, a partir das histórias de vida contadas empreendedoras do estado de Santa Catarina, todas tiveram contratempos em suas histórias como empreendedoras. Os principais problemas encontrados ao longo do processo empreendedor foram pessoais e familiares, financeiros, dificuldades de gestão, falta de credibilidade e dificuldades de mercado. Preconceito, falta de respeito e da credibilidade das pessoas com quem as mulheres se relacionam, notadamente aquelas que atuam em setores tradicionalmente masculinos. As dificuldades de conciliar múltiplos papéis como mães, esposas e empresárias foi outro problema relatado pelas mulheres. $\mathrm{O}$ fato da criação dos filhos estar atrelado à mãe na estrutura familiar é predominante nos relatos das empreendedoras, embora não citem imposição do marido quanto a trabalharem fora ou constituírem suas empresas. O sentimento de culpa, entre as mães foi constatado, cujo convívio com os filhos foi prejudicado em função da dedicação ao empreendimento. Essa difícil decisão, por fim, é encarada como um sacrifício necessário para garantir o bem estar familiar. Assim, o prazer advindo do processo empreendedor, resultante da maior liberdade e flexibilidade, é temperado por descontentam ento, em função das demandas de tempo entre as necessidades de equilibrar as exigências do negócio e os interesses dos filhos (ALPERSTEDT et al., 2014).

Por esse motivo, ao analisar a inserção das mulheres como empresárias, torna-se interessante considerar alguns aspectos comuns ao comportamento de pessoas que obtiveram sucesso na gestão de seus negócios, bem como outras características específicas à conduta empresarial feminina, assim como o histórico da evolução e das conquistas dessas mulheres que residem e empreendem na Região Metropolitana de Belém - Pa.

\section{Trajetória metodológica}

A área de abrangência do estudo é a Região Metropolitana de Belém - RMB, que, de acordo IPEA (2016), compreende os municípios de Ananindeua, Belém, Benevides, Marituba, Santa Bárbara do Pará e Santa Isabel do Pará. Essa área é de significativa importância dentro do contexto econômico, uma vez que o número de microempreendedoras individuais que estão alocadas em atividades localizadas nesses municípios concentra mais de $80 \%$ das microempresas individuais do estado do Pará.

Trata-se de uma pesquisa exploratória em sua essência. Para a obtenção do máximo de informações acerca das mulheres empreendedoras do Pará, foram utilizadas três técnicas de investigação qualitativas: entrevistas, análise de documentos e observação participante, e uma técnica quantitativa, a realização de levantamento.

Primeiramente, como forma de obter entendimento sobre a trajetória dessas mulheres empreendedoras, foram realizadas entrevistas junto aos consultores especialistas que atuam no Sebrae na área do projeto Microempreendedor Individual - MEI, os quais eram em número de 19 consultores em outubro de 2015. Essa etapa se mostrou importante, promovendo entendimento inicial para as justificativas de formalização, haja vista a experiência por eles

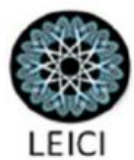


acumulada. Em seus estudos Bomfim e Teixeira (2015), corroboraram por meio de entrevistas realizadas com as empreendedoras, a ideia de utilizar o Sebrae como veículo de acesso às informações.

Na sequência, se obteve acesso a todos os atendimentos do Balcão Sebrae relativos aos registros das mulheres microempreendedoras no ano de 2015. Desses registros pode-se analisar a demanda por informações das mulheres microempreendedoras individuais, tais como necessidade de melhorar os conhecimentos de gestão empresarial, tecnologia, processos e outros, e a forma de obtê-los.

A terceira e última técnica de pesquisa qualitativa, foi utilizada no intuito de corroborar e enfatizar as informações apreendidas por meio das entrevistas e da análise documental. Tratase do uso da técnica de observação in loco, durante o mês dedezembro de 2015, nos boxes de atendimentos do Sebrae em Belém, observando cada consulta realizada pelos consultores às microempreededoras. O Sebrae permitiu o registro dos dados e em alguns momentos foram solicitadas informações complementares aos consultores e também às microempreendedoras. Ressalta-se que essa técnica foi realizada junto ao balcão de atendimento dos consultores do Sebrae, a fim de observar as principais demandas por atendimento e orientação das microempreendedoras.

Por fim, foi utilizada uma técnica quantitativa, com uso de bases primárias de dados, obtidos por meio da aplicação de questionários (levantamento). Ressalta-se o apoio do Serviço Brasileiro de Apoio às Micro e Pequenas Empresas - Sebrae, o qual fornceceu uma base de dados com contatos e dados demográficos das microempreendedoras individuais formalizadas na RMB. Essa base contempla as seguintes variáveis: perfil, escolaridade, estado civil, idade, pessoas ocupadas, tipos de negócios, recursos materiais e imateriais utilizados e formalização.

Para a definição da população e dos critérios de inclusão da amostra para a pesquisa foi utilizado o banco de dados do Sebrae, A população da pesquisa abrangeu o universo dos microempreendedores individuais da RMB, que, de acordo com o referido banco de dados, existe desde a criação do microempreendedor individual, em julho de 2009, com recorte temporal em agosto de 2015. Essa base de dados possuia um total de 159.362 microempreendedores, dentre ativos, inativos e desenquadrados (os que obtiveram receitas superiores ao limite previsto em lei para os microempreendedores, haja vista os padrões que são impostos de acordo com a Lei Complementar 128 de 2008 (Lei Geral do MEI)).

Assim, do banco de dados inicial, foram analisadas apenas os microempreendedores ativos, em número de 65.489, e destes, separados os do gênero masculino (em número de 35.510 - 54.2\%) restando 29.979 ou (45.8\%) de microempreendedoras femininas, sendo que na consideração do universo da região metropolitana de Belém, a base de microempreendedoras ativas foi de 25.175 pessoas, assim representadas: Belém 62\%, Ananindeua 25\%, Castanhal $5 \%$, Marituba 3\%, Santa Isabel 2\%, Benevides 2\% e Santa Bárbara 1\%. e, Assim, trata-se de pesquisaamostral, probabilística proporcional e com a garantia de aleatoriedade constituída pela proporcionalidade e quociente entre o total da amostra.

O levantamento foi realizado em uma amostra representativa, utilizando margem de erro de $5 \%$ e intervalo de $95 \%$ de confiança. A fórmula para o cálculo do tamanho da amostra é apresentada a seguir:

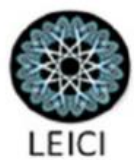




$$
n=\frac{\partial^{2} \cdot p \cdot q}{e^{2}}
$$

Onde: $\mathrm{n}=$ Tamanho da amostra;

$\partial^{2}=$ Nível de confiança escolhido, expresso em número de desvios-padrão;

$\mathrm{p}=$ Percentagem com a qual o fenômeno se verifica;

$\mathrm{q}=$ Percentagem complementar $(100-\mathrm{p})$;

$\mathrm{e}^{2}=$ Erro máximo permitido.

O resultado indicou uma amostra representativa com um total de 137 microempreendedoras individuais sendo: 85 em Belém, 35 em Ananindeua, 8 em Castanhal, 1 em Santa Bárbara, 2 em Benevides, 4 em Marituba e 2 em Santa Isabel, independentemente da atividade desenvolvida ou qualquer outra característica.

O questionário de pesquisa constou de perguntas fechadas e abertas, tendo sido dividido em quatro partes. Primeiramente (Parte I) o instrumento utilizado visou obter informações gerais de identificação da microempresária, ano de formalização e descrição da atividade preponderante. A Parte II diz respeito às informações sobre o que levou as mulheres a serem microempreendedoras individuais. Nessa etapa foram resgatados os principais estímulos para o comportamento emprendedor feminino conforme a literatura estudada (HISRICH, 1989; VOKINS IN ALLEN; TRUMAN, 1993; MOORE; BUTTNER, 1997; CROMIE, 1998; GIMENEZ et al., 1998; STILL; TIMMS, 1998, LINDO et al., 2007; GUIMARÃES, 2011; BODEN JR., 1999; KORN FERRY, 2001; POSSATI; DIAS, 2002; FREITAS; TEIXEIRA, 2016). Buscaram-se as especificidades do trabalho, haja vista poder efetivamente se instalar parâmetros de acompanhamento, mudança de atividade e ou opção por um novo empreendimento ou ainda o desafio por algo novo. A Parte III do instrumento de pesquisa tratou das questões que identificam a opção pela formalização (GEM, 2012; BOTTANE; LIMA, 2012; SANTOS et al., 2012). A parte IV do instrumento de pesquisa visou a obtenção de informações complementares com respeito ao gênero e o empreendedorismo, dando aporte teórico sobre o trabalho feminino e o empreendedorismo. Por fim, as informações levantadas por meio do levantamento foram tratadas com estatísticas descritivas.

\section{Resultados e análise}

\subsection{Trajetória empreendedora}

De acordo com os dados do Balcão do Sebrae, em 2015 foram realizadas 19.476 consultas na RMB buscando informações sobre como atuar como MEI, um número expressivo e significativo de pessoas interessadas. Sendo que metade das consultas realizadas foi realizadas por mulheres (50,05\%). Quando analisados comparativamente os municípios, observa-se que Belém recebeu $73,21 \%$ das consultas.

A análise dos prontuários das consultas realizadas no Balcão Sebrae indicou que grande parte das microempreendedoras buscaram informações para o desenvolvimento das atividades, bem como buscando orientações para novas oportunidades de apresentação para os produtos que produzem, por meio de cursos, feiras, missões e caravanas, fortalecendo o marketing empresarial, posicionando o produto e garantindo sua comercialização. Isso demonstra a busca dessas empreendedoras pela sustentabilidade dos negócios, além da manutenção e o desenvolvimento dos processos produtivos.

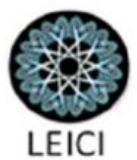


Na sequência dos trabalhos foram entrevistadas 140 microempreendedoras da RMB. Caracterizando essas mulheres, observou-se que, $80 \%$ são solteiras, viúvas ou separadas, sendo, portanto, grande parte dessas mulheres responsáveis pelo sustento do lar. Os dados da pesquisa indicaram que, para 90,5\% das empreendedoras, essa é uma fonte importante na composição da renda familiar, sendo que em $54,7 \%$ é a principal renda da família. Ressalta-se a idade de atividade dessas mulheres. Entre as empresárias, 41,3\% têm entre 18 e 39 anos e 58,7\% estão na faixa de 40 a 64 anos. Ou seja, todas as entrevistadas estão em idade laboral para o desenvolvimento de atividades produtivas.

A escolaridade das entrevistadas é, na sua maioria, nível médio ou técnico completo (51\%) ou fundamental completo (25\%), constituindo a base para o desenvolvimento dos negócios e a inovação. Estes dados corroboram com as informações colhidas junto aobalcão de atendimento do Sebrae, no qual 50,56\% das mulheres que acessaram a informação possuem médio completo. Adiciona-se aos dados, o estudo de Araújo e Araújo (2013) sobre a inovação entre empreendedores do setor de serviços de restaurantes, que identificou que $60 \%$ das inovações de processo ocorriam entre empreendedores com ensino médio completo e $15 \%$ entre o ensino fundamental. Dentre aquelas que estão no nível superior ou concluíram tem-se $20 \%$. Os extremos são: fundamental incompleto e nível de pós-graduação, com $2 \%$ cada.

Observa-se que, se por um lado, a escolaridade não é um fator motivacional, nem impeditivo para que essas mulheres empreendam seus próprios negócios, em outra mão aquelas mulheres que não possuem nível superior são o grupo mais representativo. No Brasil, pessoas com escolaridade até o nível médio recebem salários baixos e empreender por conta própria é uma alternativa viável para melhorar a renda familiar.

Essa percepção é corroborada pelos resultados da pesquisa, que indicou que, entre os principais motivos que as levaram a um negócio, tem-se que:

- 52,6\% da mulheres afirmaram que empreendem para ganhar seu próprio dinheiro;

- $35,9 \%$ afirmaram que empreendem para aumentar a renda da família;

- $7,7 \%$ para aumentar o prestígio social;

- $3,8 \%$ indicaram outros motivos, tais como a necessidade e a falta de outras oportunidades no mercado formal de trabalho.

Esses resultados corroboram os estudos de Boden Jr. (1999), Korn/Ferry (2001) e Possati e Dias (2002), os quais destacaram, que, entre os principais motivos que fundamentam a opção das mulheres pelo empreendedorismo sobressai a necessidade de sobrevivência, a descoberta de um nicho de mercado, a busca pela auto realização e a independência e/ou estabilidade financeira.

Vale frisar que o empreendedorismo oferece para a maior parte das mulheres a oportunidade de realização de um sonho, tanto no que diz respeito à possibilidade de se colocar em prática uma atividade desejada quanto à probabilidade de melhoria das condições financeiras.

Quanto às atividades desenvolvidas, tem-se que:

- 58,5\% atuam no ramo de comércio, como por exemplo: ótica, vestuário e calçados, farmácias, bares, lojas de produtos veterinários e lojas de informática;

- $30,4 \%$ são atividades de prestação de serviços, sendo, por exemplo: fornecimento de alimentos, contabilidade, acabamento em gesso, cabeleireiro, manicure e pedicure e, manutenção de equipamentos e;

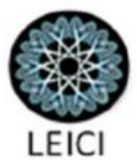


- $11,1 \%$ são atividades da indústria, tais como: artesanato, padarias e fabricação de produtos à base de celulose.

Um dado bastante representativo levantado na pesquisa é a experiência anterior no ramo que as entrevistadas escolheram para empreender. Segundo a pesquisa, 66,4\% dentre as pesquisadas já possuíam experiência anterior, revelando um conhecimento prático importante para a operação dos negócios.

Junto com as atividades empreendedoras desenvolvidas individuais, 49,6\% das MEIs alegram que ainda possuem outras ocupações paralelas à atividade principal, que são representadas por trabalhos domésticos tais como: o cuidado com a casa e os filhos, e trabalhos externos como lavagem de roupa; venda de perfumes e cosméticos; costura e artesanatos. Algumas incluem a atividade de ser estudante, o que, normalmente, ocorre à noite em função dos compromissos diurnos e vespertinos. Ao se analisar esses referenciais, verifica-se a preocupação com a qualificação além do empoderamento dos conhecimentos que fazem com que as microempreendedoras individuais garantam diferenciais competitivos no mercado de trabalho.

Ademais, para Cherlin (2001), uma vida cheia de ocupações, contemplando o trabalho externo e interno, proporciona satisfação e sentimento de realização. Tiedge (2004) assevera que, transitar simultaneamente nos espaços públicos e privado (representado pelo lar) têm consequências positivas e pode ser gratificante e não um fardo. Assim, o empreendedorismo torna-se uma alternativa de inclusão social e econômica dessas mulheres no universo do trabalho, possibilitando ainda a realização das tarefas domésticas, como o acompanhamento dos filhos e sua vida escolar. Na pesquisa, todas as entrevistadas afirmaram que lutavam pela possibilidade de serem independentes e poderem mostrar às famílias que conseguiram conquistar o seu espaço. Estes dados corroboram com o estudo de Cortez et al., (2016) realizado na cidade de Natal, Rio Grande do Norte, que evidenciaram a relação trabalho-família como um importante impulsionador para o desenvolvimento do negócio das mulheres não somente por razões psicológicas quanto ao fato de que devido à falta ou o restrito acesso aos financiamentos bancários, que ocorre tanto por discriminação nas relações de gênero quanto por dependência financeira do marido ou dos pais, estimula que esse suporte parta de suas próprias famílias.

Aqui cabe complementar com a percepção dos consultores do Sebrae, que foram entrevistados. De acordo com esses profissionais, de modo geral as mulheres são mais organizadas em seus negócios comparativamente aos homens e planejam a gestão com mais eficiência, além de cumprirem mais prazos e metas, como por exemplo, cronograma de atividades e pagamentos. Quanto à organização, sem dúvida as mulheres mantêm essa característica no ambiente público, decorrente muitas vezes de uma postura que trouxe da base familiar pela execução de atividades desenvolvidas no espaço privado (casa) simultaneamente às atividades empreendedoras e com pequenos espaços de tempo.

Os consultores afirmaram ainda que as mulheres são mais participativas, têm iniciativa e evitam gastos desnecessários; são mais atenciosas quanto ao atendimento ao cliente; mais detalhistas e mais receptivas as mudanças. Isso decorre em virtude da necessidade de melhoria das empresas, que para $95 \%$ dos consultores entrevistados é mais presente na mulher. As respostas dizem respeito, principalmente, ao fato da mulher ser mais sensível, cuidadosa, estar preocupada em ter uma atividade e se desenvolver como pessoa buscando diferenciais que

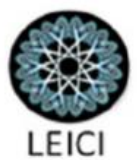


garantirão sua permanência e atuação, seja nos epaços públicos, concomitante com a manutenção do lar, corroborando os estudos de Bourne (2010).

Esse movimento incentivou as mulheres empreendedoras para o desenvolvimento pessoal e profissional, culminando em um processo bem sucedido de qualificação e empoderamento feminino.

\subsection{Qualificação e empoderamento das microempreendedoras Individuais}

$\mathrm{Na}$ análise realizada pelos consultores do SEBRAE durante as entrevistas concedidas, foi destacada a preocupação com o aprendizado acerca de processos e controles, comum dentre as microempresárias e mais acentuada nessas, comparativamente aos homens, o que decorre da mulher sempre buscar o novo como diferencial, encontrando-o somente no conhecimento e na capacitação.

Sobre essa afirmação, ao realizar a análise, os consultores destacaram que os homens, normalmente, são mais práticos e querem respostas mais rápidas, enquanto as mulheres, mais pacientes e perseverantes, buscam novos conhecimentos para agregarem diferenciais competitivos.

É importante destacar que $63,5 \%$ das entrevistadas declararam que se prepararam ou buscaram conhecimentos para posteriormente se transformarem em microempreendedoras individuais. Entre os mecanismos para a qualificação que utilizaram, pode-se destacar:

- que $75,2 \%$ das empreendedoras buscaram orientações técnicas de instituições como o próprio Sebrae;

- que $57,7 \%$ das empreendedoras participaram de cursos e palestras;

- que $45,3 \%$ buscaram conhecimentos na internet;

- entre outras formas de buscar conhecimento, como na busca pela orientação de conhecidos que já atuam no setor $(19,7 \%)$ e na leitura de cartilhas e outros materiais impressos $(16,1 \%)$.

Além da preparação para atuar como empreendedora, $67,9 \%$ das participantes da pesquisa declarou que possuem um planejamento do negócio e 65,7\% continuam participando de cursos e treinamentos, frequentemente, para se atualizar.

Sobre as áreas de interesse as microempreendedoras têm participado de cursos, principalmente, nas áreas administrativas (78,3\%), financeira e custos (55\%), gestão e processos $(47,3 \%)$ e marketing $(33,3 \%)$. Assim, pode-se notar que elas estão preocupadas com treinamentos e aperfeiçoamentos visando à competitividade e melhorias de processos, ao procurar por treinamentos, inovações, seminários, rodas de negócios, feiras e oficinas e orientação técnica.

Analisando esse processo de mudança de comportamento e empoderamento das mulheres microempreendedoras individuais, Mosedali (2005) e Sardenberg (2009) destacam que o empoderamento das mulheres implica no seu processo da conquista da autonomia e autodeterminação, da capacidade de tomar decisões de peso em relação as suas vidas e de leválas a termo, portanto, de assumir controle sobre suas vidas.

Nesse sentido, Fernandes, Lopes, Watanabe, Yamaguchi e Godoi (2016), em pesquisa realizada no Brasil, observaram que o empreendedorismo oportunizou às mulheres empreendedoras o empoderamento econômico, tendo em vista a ampliação da renda, a independência financeira e autovalorização declarada pelas empreendedoras entrevistadas.

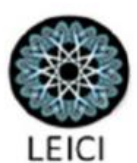


Esses autores ainda investigaram o empoderamento nas dimensões psicológica, educacional, política e familiar, mas nessas dimensões as entrevistadas demonstraram certo grau de dependência e insegurança na tomada de decisão e direcionamento do próprio negócio.

É importante salientar que $60,6 \%$ das microempreendedoras individuais geram pelo menos mais um posto de trabalho direto, e desse total. 63,5\% informaram que o colaborador não é membro da família. Isso demonstra que as microempreendedoras individuais pesquisadas têm preocupação em manter o seu negócio realmente como uma atividade que não seja influenciada por parentes.

As atitudes das empreendedoras corroboram os estudos de Leon (2009), para quem o empoderamento inclui tanto a mudança individual quanto as ações coletivas, e Mosedali (2005), o qual destaca que o empoderamento é um processo, não existindo um estágio de empoderamento absoluto. As pessoas são empoderadas e desempoderadas em relação às outras, ou então, em relação a si próprias. Assim, observou-se entre as empreendedoras que participaram da pesquisa que é um grande orgulho poder ter o seu negócio, dirigi-lo sem precisar dos outros e poder mantê-lo para provar que elas têm capacidade.

Por fim, quando questionadas quanto à existência de barreiras no desempenho da atividade pelo fato de ser mulher, $85,4 \%$ disseram que não perceberam tais barreiras e 14,6\% apenas responderam sim, justificando que o fato de ter uma mulher à frente de um negócio, muitas vezes traz falta de credibilidade devido à mesma desempenhar atividades domésticas concomitantes com as atividades empresariais, como observado nos estudos de Belle (1993), um preconceito de maneira discreta e sutil, onde a mulher encontrava dificuldades no mercado de trabalho que não eram encontradas pelos homens (BELLE, 1993)

\subsection{A formalização do negócio}

Grande parte das empreendedoras $(86,1 \%)$ declarou que a formalização contribuiu para melhoria de seu negócio. Entre os pontos de melhoria, afirmam que suas vendas aumentaram com a formalização principalmente pela possibilidade de competir de igual para igual com as outras empresas, devido à facilidade de emissão de nota fiscal; melhor gestão; fazer compras com CNPJ; formalizar o atendimento e a fidelização dos clientes e; ter referência formal junto às instituições financeiras e aos próprios clientes.

Os consultores, quando entrevistados, destacaram outras vantagens da oportunidade de poder ser MEI, tais como: a formalização facilitada, o baixo custo de regularização; a oportunidade de ter benefícios de assistência social; poder ter um empregado; emitir nota fiscal; e, pagar uma taxa fixa mensal.

Com a formalização $91,2 \%$ das microempreendedoras passaram a controlar melhor os resultados utilizando instrumentos de controle como: planilha de gastos, programas de computador, melhor planejamento do fluxo de caixa, programas de gestão e outros. Ademais, $51,1 \%$ implementou ações de inovação com novos equipamentos, promoções de novos mercados e parcerias, controle financeiro e produtos novos. De modo geral, $70,8 \%$ afirmaram que implementaram melhorias após a formalização do negócio.

Outras percepções de melhoria com a formalização foram declarações de maior controle e melhor aproveitamento do tempo, melhorias nas organizações através de qualificações e treinamentos para atendimento ao cliente, melhor layout; atualização na fabricação de produtos e realização de pesquisa de mercado. Do universo pesquisado, $75,2 \%$ das microempreendedoras

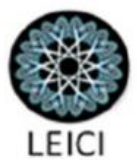


reduziram os desperdícios pela conscientização e aprendizado visando à otimização de recursos e matérias primas.

Com a formalização, melhorou a qualificação profissional para $72,3 \%$ das entrevistadas, baseado, principalmente, na efetivação de cursos de atualização como relação interpessoal; uso de máquinas e equipamentos; além de cursos, palestras, feiras e seminários visando melhor conhecimento do negócio. Como reflexo, $42,3 \%$ das pesquisadas declararam que estudam o mercado buscando maior competitividade e $35 \%$ declararam que estudam os concorrentes.

Durante as entrevistas com os consultores, estes afirmaram que as mulheres MEIs, na maior parte dos casos, percebem mais as vantagens da formalização que os homens MEIs. Entre as pesquisadas, 77,4\% declararam aumento do faturamento dos negócios; e somente para $0,70 \%$ das entrevistadas os negócios diminuíram. Enquanto para 21,9 não souberam responder ou não perceberam crescimento dos negócios.

Assim, a despeito das dificuldades que todo empreendedor enfrenta, e das particularidades de ser mulher empreendedora, 89,1\% das entrevistadas declararam que vão continuar atuando na atividade de microempreendedora individual, e que pretendem ampliar seus negócios, destacando que $90,5 \%$ das mulheres participantes estão satisfeitas ou plenamente satisfeitas com a sua atividade laboral.

\section{Considerações Finais}

Essa pesquisa teve como objetivo compreender a atuação da mulher microempreendedora individual - MEI da região metropolitana de Belém-Pa., considerando suas motivações para exercer a atividade empreendedora, a contribuição para o empoderamento feminino e as percepções acerca da formalização e do crescimento dos negócios pelas microempreendedoras.

Dessa forma, com base nos métodos de investigação adotados, foi possível observar que as microempreendedoras individuais que estão à frente de seus negócios da Região Metropolitana de Belém estão concentradas no setor do comércio, atuando em atividades diversificadas, tais como vestuário e calçados, farmácias, bares e lojas de informática, mas também atuando com o fornecimento de alimentos, contabilidade, manutenção de equipamentos, fornecimento de pães, entre outras atividades. Esse primeiro ponto desmistifica o perfil do senso comum de que as mulheres trabalham somente em artesanato e outras atividades mais direcionadas à mulher, como por exemplo, salões de beleza. .A participação da mulher nas microempresas individuais é crescente e não está segmentada apenas em ocupações tradicionalmente femininas.

Como um segundo ponto, se destacou a forma como as microempreendedoras desempenham a gestão: forma participativa, haja vista a sensibilidade, organização e o planejamento dos negócios. Para integrar o Programa Microempreendedor Individual, com base na análise das consultas realizadas no Balcão Sebrae, foi observado que a maioria das informações que são solicitadas pelas mulheres está relacionadas à organização, planejamento e melhor gestão dos processos operacionais.

Outra questão interessante observada é o interesse das mulheres em buscar primeiramente um grau de preparação, acumulando conhecimentos úteis para o desenvolvimento do negócio, tanto de ordem da melhoria da escolaridade formal, credenciando-se ao ensino médio e ao ensino superior, tanto como buscando outras modalidades de desenvolvimento pessoal, por meio de palestras, seminários, feiras, rodada de negócios. Há interesse de melhoria de

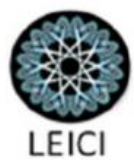


conhecimento nas áreas administrativa, financeira, custos, gestão e processos e outros visando à competitividade e sustentabilidade do negócio.

Quanto à formalização, vale ressaltar que motivos diferenciados levaram as mulheres a buscar a formalização de seus negócios, destacando-se em quase noventa por cento delas que empreendem para ganhar seu próprio dinheiro, ou para aumentar a renda da família, demonstrando assim a importância que o empreendimento exerce sobre si e sobre a renda da família.

Assim, constata-se que as mulheres desenvolvem seus negócios de forma inovadora, visto que elas quebram paradigmas, e que, apesar de ter menos experiência gerencial as microempreendedoras conseguem controlar bem seus processos utilizando instrumentos de controle, o que novamente evidencia a busca pelo conhecimento e permanência da empresa no mercado.

A maioria das microempreendedoras pesquisadas alegou que implementou ações de inovação com aquisição de equipamentos mais adequados, busca de novos mercados e ou produtos e oferecimento de serviços diferenciados. Do ponto de vista da sustentabilidade, as mulheres microempreendedoras garantem a sustentação de seus negócios com geração de empregos, onde grande parte das microempreendedoras individuais entrevistadas gera um emprego direto, dando suporte a até mais três empregos, favorecendo assim outras famílias que dependem indiretamente desse trabalho. As empreendedoras pesquisadas reduziram desperdícios na operacionalização de seus negócios, reaproveitando matéria prima, utilizando material reciclável e ainda disseminando e tomando consciência que essas atitudes devem servir de exemplo e serem divulgadas para utilização e avanço da sustentabilidade.

Assim, conclui-se que o empreendedorismo é uma alternativa viável de inclusão social e econômica para as mulheres da Região Metropolitana de Belém-Pa., onde se destacam o crescimento pessoal, o empoderamento e a contribuição para o desenvolvimento da região onde atuam.

Como limitação da pesquisa destaca-se que a mesma foi baseada nos depoimentos colhidos durante as entrevistas realizadas com os consultores do Sebrae e o levantamento por meio de questionário aplicado às empreendedoras, podendo haver vieses e superestimações nas respostas obtidas. Como sugestões para pesquisas futuras sugere-se a realização de pesquisa junto às instituições de interesse, a fim de compreender as políticas atuantes de fomento ao empreendedorismo feminino, de forma a confrontar as expectativas e as ações concretas capazes de tornar essas mulheres cada vez mais aptas a enfrentar os desafios que o mercado apresenta.

\section{Referências}

ALLEN, S.; TRUMAN, J. M. Women entrepreneurs. Business \& Economics. London: New Fetter Lane, 1996.

ANDERSON, A. H.; WOODCOCK, P. Effective entrepreneurship: a skills and activity

based approach.Oxford, UK/Cambridge, MA: Blackwell Publishers Ltd. (1996).

ANTUNES, A. L.; PEREIRA, F. F.; SARFATI, G.; RIGHI, G. B.; et al. GEM - Global

Entrepreneurship Monitor. Empreendedorismo no Brasil. 2012.
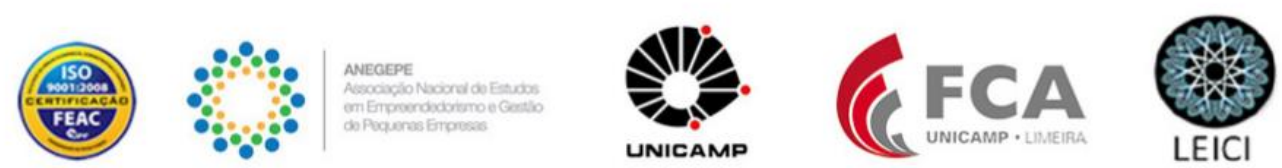
ALPERSTEDT, G. D.; FERREIRA, J. B.; SERAFIM, M. C. Empreendedorismo feminino: dificuldades relatadas em histórias de vida. Revista de Ciências da Administração, v. 16, n. 40, p. 221-234, 2014.

BODEN JR., F. J.Flexible Working Hours, Family Responsibilities, and Female Self-

Employment. American Journal of Economics and Sociology. Volume 58, Issue 1, pages 7183, January 1999.

CARTER, S. Women's Business Ownership: A Review ofthe Academic, Popular and Internet Literature.Glasgow: University of Strathclyde, 2001.

CENSO IBGE. Estatística da População de trabalho e rendimento. Disponível em: http://www.ibge.gov.br/home/estatistica/populacao/trabalhoerendimento/pnad2003/. 2003.

CHERLIN, A. J. Public and Private Families: An Introduction (3rd ed.). New York: McGraw Hill. (2001).

CORTEZ, A. E. G.; FERREIRA, T. B.; FERREIRA, C. M.; ARAÚJO, A. G. Cognição e Afetividade nas Trajetórias Empreendedoras das Mulheres da Cidade do Natal - RN. Revista de Empreendedorismo e Gestão de Pequenas Empresas, v. 5, n. 2, p. 1-27, 2016.

CRAMER, L. et al. Representações Femininas da Ação Empreendedora: Uma Análise da Trajetória das Mulheres no Mundo dos Negócios. Revista de Empreendedorismo e Gestão de Pequenas Empresas - REGEPE, v.1, n.1, jan/abril de 2012.

DAMASCENO, L. D. J. Empreendedorismo Feminino: Um Estudo Das Mulheres Empreendedoras Com Modelo Proposto Por Dornelas. FLACSO - Instituto da Mulher. Faculdade 7 de Setembro - FA7. Fortaleza - CE, 2010.

DORNELAS, J. Brasil é o país que possui a maior taxa de empreendedores no G20.

2011. Disponível em: <http://www.josedornelas.com.br/artigos/o-brasil-e-o-pais-que-possuia-maior-taxa-de-empreendedores-no-g20/> Acesso em: 15/06/2015.

EVANS, L. Veja as Vantagens e Desvantagens de Formalizar o Negócio em Tempos de Crise. Disponível em:

http://www.em.com.br/app/noticia/economia/2015/06/01/internas_economia,653469/veja-asvantagens-e-desvantagens-de-formalizar-o-negocio-em-tempos-de.shtml Acessado em: 02 de Jun de 2015.

FERNANDES, T. D. S.; LOPES, G. S. C.; WATANABE, M.; YAMAGUCHI, C. K.; GODOI, C. K. Dimensões do Empoderamento Feminino: Autonomia ou Dependência? .

Revista Alcance, v. 23, n. 3, p. 391-413, 2016.

FREITAS, R. K.; TEIXEIRA, R. M. Identificação de Oportunidades Empreendedoras por Mulheres. Revista Economia \& Gestão, v. 16, n. 44, p. 81-108, 2016.

GIMENEZ, F.; FERREIRA, J.M.; RAMOS, S.M. Empreendedorismo E Estratégia De Empresas De Pequeno Porte 3Es2Ps. Curitiba, 2010.

GIMENEZ, F. A. P.; FERREIRA, J. M.; RAMOS, S. C. Empreendedorismo Feminino no Brasil: Gênese e Formação de um Campo de Pesquisa. Revista de Empreendedorismo e Gestão de Pequenas Empresas, v. 6, n. 1, p. 40-74, 2017.

GUIMARÃES, Sonia k. A Nova Sociologia Econômica E O Retorno Do Empreendedor. XV Congresso Brasileiro De Sociologia. Curitiba, jul. 2011.

HISRICH, R.D.; PETERS, M.P.; SHEPHERD, D.A. Empreendedorismo - AMGH Editora LTDA, $9^{a}$ edição, bookman 2014.
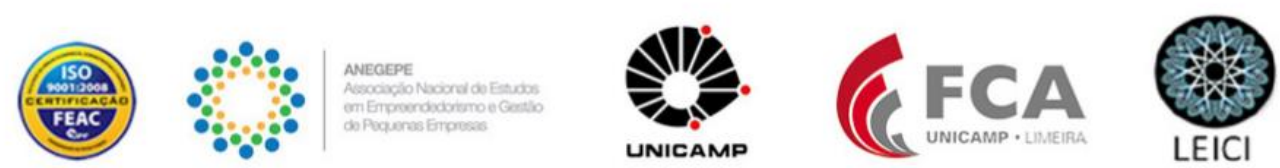
IBGE. Perfil dos Municípios Brasileiros - 2009. Disponível em:

<http://www.ibge.gov.br/home/estatistica/economia/perfilmunic/2009/>. Acessado em: 15 de Jul de 2015.

IPEA. Região metropolitana de Belém. Acesso em 01/03/2016. Disponível em:

$<$ http://www.ipea.gov.br/redeipea/images/pdfs/governanca_metropolitana/projeto_governanc a_oficina1_pa.pdf $>$.

KORN/FERRY INTERNATIONAL. (2001). What women want in business: a survey of executives and entrepreneurs.Retirado de <

http://www.kornferry.com/institute/files/pdf1/What_Women_Want_in_Business1.pdf> LINDO, M. R., CARDOSO, P. M., RODRIGUÊS, M. E., \& WETZEL, V. (2007). Vida pessoal e vida profissional: os desafios de equilíbrio para mulheres empreendedoras do Rio de Janeiro. Revista de Administração Contemporânea - RAC, 1(1), 1-15. Recuperado em 28 set. 2008, em http://www.anpad.org.br/.

MACHADO, H. Retired and Entrepreneurs: case studies with women in Brazil. Interactive Research Forum First International Conference of Iberoamerican Academy of Management. Madrid, December 9 to 11th , 1999.

MACHADO, Hilka V et al. O Processo De Criação De Empresas Por Mulheres. RAE eletrônica, v.2, n.2, p.1-22, 2003.

MACHADO, Hilka V. et al. Mulheres Empreendedoras: Retrospectiva E Perspectivas De Estudos. Encontro Nacional de Pós-graduação em Administração ENANPAD, Rio de Janeiro, 2010. CD-ROM.

MOORE, D. P., BUTTNER, E. H. (1997). Women Entrepreneurs: Moving Beyond The Glass Ceiling. Thousand Oaks, CA: Sage Publications.

POSSATI, I. C., DIAS, M. R. Multiplicidade De Papéis Da Mulher E Seus Efeitos Para O Bem-Estar Psicológico. Psicologia: Reflexão e Crítica, 15(2), 293-301. (2002).

SARDENBERG, C. M. B. Liberal vs Liberating Empowerment: Conceptualising Women's Empowerment from a Latin American Feminist Perspective.Brighton: IDS: Pathways of Women's Empowerment, Pathways Working Paper 7, July 2009.

Sebrae. Boletim de formalização das MPEs. Disponível em:

http://www.boletimdoempreendedor.com.br/boletim.aspx?codBoletim=103 . 02/07/2016

Sebrae. Base de Dados Anual do Sebrae. 2015.

Sebrae, CNI. CNI E Sebrae Anunciam Empresas Vencedoras Do Prêmio Nacional De Inovação. 2014.

SILVEIRA, A., GOUVEA, A. B. C. T. Empreendedorismo Feminino: Mulheres Gerentes de Empresas. Vol. 7, №3 - Julho/Setembro de 2008.

SOBRAL, F. O Processo Empreendedor. 2010.

TEIXEIRA, R. M.; BOMFIM, L. C. S. Empreendedorismo feminino e os desafios enfrentados pelas empreendedoras para conciliar os conflitos trabalho e família: estudo de casos múltiplos em agências de viagens. Revista Brasileira de Pesquisa em Turismo, v. 10, n. 1, p. 44-64, 2016.

TIEDGE, L. B. Processes Of Change In Work/Home Incompatibilities: Employed

Mothers. 1986-1999. Journal of Social Issues, 60 (4), 787-800. (2004).
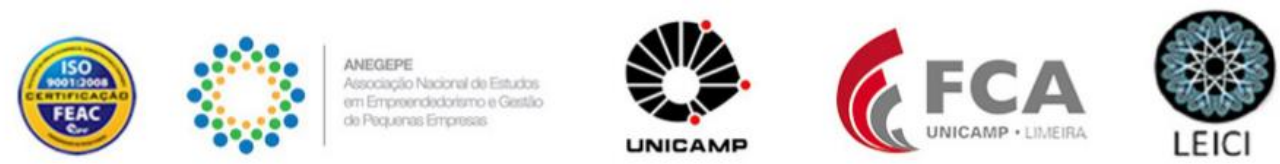